\title{
Stormtime dynamics of the global thermosphere and equatorial ionosphere
}

\author{
W. J. Burke ${ }^{1,2}$, C. Y. Huang ${ }^{1}$, and R. D. Sharma ${ }^{1}$ \\ ${ }^{1}$ Space Vehicles Directorate, Air Force Research Laboratory, Hanscom AFB, MA, USA \\ ${ }_{2}^{2}$ Institute for Scientific Research, Boston College, Chestnut Hill, MA, USA \\ Received: 13 October 2008 - Revised: 6 February 2009 - Accepted: 13 March 2009 - Published: 5 May 2009
}

\begin{abstract}
During magnetic storms the development of equatorial plasma bubbles (EPBs) and distributions of thermospheric densities are strongly influenced by the histories of imposed magnetospheric electric $\left(\varepsilon_{\mathrm{M}}\right)$ fields. Periods of intense EPB activity driven by penetration $\varepsilon_{\mathrm{M}}$ fields in the main phase are followed by their worldwide absence during recovery. A new method is applied to estimate global thermospheric energy $\left(E_{\mathrm{th}}\right)$ budgets from orbit-averaged densities measured by accelerometers on polar-orbiting satellites. During the main phase of storms $E_{\text {th }}$ increases as long as the stormtime $\varepsilon_{\mathrm{M}}$ operates, then exponentially decays toward quiet-time values during early recovery. Some fraction of the energy deposited at high magnetic latitudes during the main phase propagates into the subauroral ionospherethermosphere where it affects chemical and azimuthal-wind dynamics well into recovery. We suggest a scenario wherein fossils of main phase activity inhibit full restoration of quiettime dayside dynamos and pre-reversal enhancements of upward plasma drifts near dusk denying bottomside irregularities sufficient time to grow into EPBs.
\end{abstract}

Keywords. Ionosphere (Electric fields and currents; Ionosphere-atmosphere interactions; Ionospheric irregularities)

\section{Introduction}

Recent growth in understanding the electromechanical forces that couple the magnetosphere-ionosphere-thermosphere system has practical consequences for calculating trajectories of objects in low Earth orbit (LEO) and improving transionospheric communications. Here we examine physical processes that commonly occur during magnetic storms

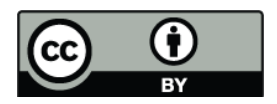

Correspondence to: W. J. Burke (afrl.rvb.pa@hanscom.af.mil) with consistent effects on these disparate space applications. Stormtime dynamics of the thermosphere are effects of complex external and internal forcing. In most instances measurements of critical parameters are absent. Thus, we must construct synthetic pictures from piecemeal measurements acquired over the course of many magnetic storms. Our present goal is to illustrate that understanding in one area affects our grasp of the other and points to further questions suggesting still deeper unity.

The paper has three main parts. The first describes stormtime properties of equatorial plasma bubbles (EPBs) as observed by satellite-borne sensors. Intense EPB activity in the main phase is followed by prolonged absences during recovery. The second introduces a new method for using measurements from accelerometers on polar-orbiting satellites to predict the evolution of stormtime thermospheric energy budgets $E_{\text {th }}$. On a globally-averaged scale the thermosphere returns to baseline values $\sim 10 \mathrm{~h}$ after stormtime electric fields abate. The third section investigates local thermosphere-ionosphere coupling mechanisms responsible for prolonged absences of EPBs at topside altitudes during the recovery phases of magnetic storms. Specifically, we consider how changed chemical composition, plasma density and neutral wind distributions may continue to affect the redevelopment of pre-reversal enhancements (PREs) of vertical plasma drifts near the dusk terminator for several days into recovery (Fejer et al., 2008).

\section{Stormtime equatorial plasma bubbles}

EPBs are plasma density depletions found in the topside ionosphere at low magnetic latitudes after sunset. They originate as small-amplitude irregularities in the bottomside of the equatorial F-layer and grow via the generalized Rayleigh-Taylor (R-T) instability (Scannapieco and Ossakow, 1976). Electric fields with eastward components

Published by Copernicus Publications on behalf of the European Geosciences Union. 


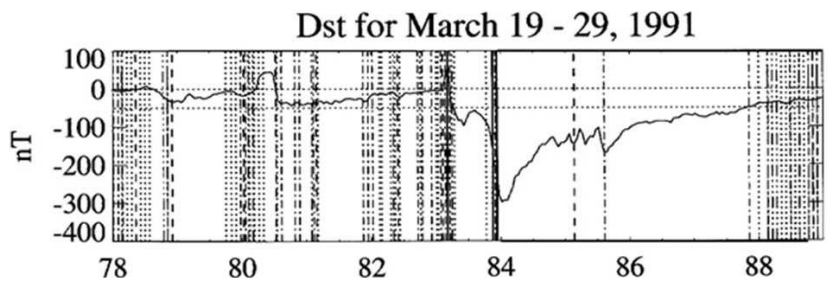

Fig. 1. $D_{s t}$ trace for 19-29 March 1991. Vertical lines indicate times of EPB detections by the plasma density monitor on DMSP F9 near the 21:00 LT meridian.

accelerate the evolution of initial density perturbations into full grown bubbles that penetrate the F-layer peak and rise through the topside ionosphere (Ott, 1978). Three sources of eastward electric fields have been identified: (1) quiettime dynamos responsible for PREs of upward plasma drifts near sunset, (2) penetration of polar electric fields to low latitudes, and (3) wind fields associated with atmospheric gravity waves. Solar heating drives eastward thermospheric winds in the afternoon sector that support the buildup of polarization charges near the dusk meridian responsible for the PRE (Farley et al., 1986; Haerendel and Eccles, 1992) observed by the Jicamarca incoherent scatter radar (Scherliess and Fejer, 1997) and sensors on the ROCSAT satellite (Fejer et al., 2008). The relative contributions of Sq current leakage into the nightside ionosphere and F-layer azimuthal winds remain a subject of debate (Eccles, 1998). Sustained penetration electric fields $\left(\varepsilon_{\mathrm{M}}\right)$ have been measured in the inner magnetosphere during the main phase of magnetic storms (Wygant et al., 1998; Burke et al., 1998) and inferred from upward plasma drifts observed at Jicamarca after southward turnings of the interplanetary magnetic field (Kelley et al., 2003). Gravity-wave activity is also a plausible source of EPBs. Singh et al. (1997) provided observational evidence from the Atmospheric Explorer E satellite suggesting that long wavelength gravity waves seed bottomside density fluctuations that grow into EPBs. Alternately, Hysell and Kudeki (2004) argued that the growth rate of bottomside density variations is significantly enhanced by collisional KelvinHelmholz instabilities driven by bottomside azimuthal winds that change from westward to eastward with increasing altitude.

There are two stormtime energy sources recognized as being capable of generating electric fields with westward components at low latitudes in the dayside and evening sectors that act to suppress EPB growth. These are (1) over-shielding electric fields driven by enhanced Region 2 field-aligned currents (Kikuchi et al., 2008) and (2) disturbance dynamos generated by winds that result from Poynting and energetic particle fluxes into the high-latitude atmosphere (Blanc and Richmond, 1980; Scherliess and Fejer, 1997; Fejer and Scherliess, 1995, 1997).
Figure 1 is a plot of the $D_{s t}$ index during an 11-day interval that included the magnetic superstorm of March 1991 when $D_{s t}$ approached $-300 \mathrm{nT}$. Vertical lines mark EPB detections by the Defense Meteorological Satellite Program (DMSP) Flight 9 spacecraft at $\sim 840 \mathrm{~km}$ near 21:00 LT (Huang et al., 2001). Attention is directed to three empirical aspects of EPB detections:

1. Regular patterns of pre-storm EPB detections exemplify the season-longitude distributions found near solar maximum intervals (Gentile et al., 2006).

2. Intense EPB activity was detected during the main phase while the $D_{s t}$ trace had a negative slope. At the same time the double probe experiment on the Combined Release and Radiation Effects Satellite (CRRES) detected strong and continuous $\varepsilon_{\mathrm{M}}$ in the equatorial plane of the inner magnetosphere (cf. Fig. 2 of Wygant et al., 1998).

3. Except for two isolated detections, EPBs were absent for 4 days before the quiet-time pattern returned. These recovery-phase exceptions occurred during brief reactivations of the ring current signified by the reappearance of $\varepsilon_{\mathrm{M}}$ (cf. Fig. 3 of Wygant et al., 1998).

The prolonged absence of EPBs throughout the 4-day recovery phase is problematic. Evidence presented in Fig. 7 of Kikuchi et al. (2008) indicates that westward, over-shielding electric fields occur but only last for a few hours. On the other hand, Scherliess and Fejer (1997) estimated that disturbance dynamo action should only be effective for $\sim 30 \mathrm{~h}$ after stormtime driving ends. Clearly, better understanding of recovery-phase mechanisms and time scales is needed. We return to this point in the discussion below.

Similar EPB patterns appear during all major $\left(D_{s t}<-100 \mathrm{nT}\right)$ magnetic storms of the past two solar cycles for which DMSP data are available (Huang et al., 2002; Gentile et al., 2006). A comparison of ROCSAT and DMSP observations showed that EPBs reach topside altitudes after 20:00 LT during quiet times but at $\sim 19: 30 \mathrm{LT}$ during magnetic disturbances (Burke et al., 2004). Repeated detections of intense EPBs by multiple DMSP satellites throughout the main phases of storms confirm the persistence of penetration electric fields. A lack of EPBs in DMSP plasma density data does not imply that radiowave scintillations should also vanish during recovery. They persist. Rather, driving eastward electric fields in the post-sunset ionosphere lack the strength and/or duration needed for irregularities to grow into EPBs, before the field polarity reverses to stabilize bottomside plasma.

\section{Stormtime thermospheric energy budgets}

The US Space Surveillance Network (SSN) is responsible for tracking and predicting the trajectories of active satellites 
and space debris. The destruction of Feng Yun $1 C$ by an antisatellite weapon in January 2007 created more than 2500 new debris fragments in LEO (B. R. Bowman, private communication, 2008). The potential for Feng Yun debris and pre-existing objects to inflict severe to catastrophic damage on spacecraft operating in LEO has refocused attention on the need to enhance collision-avoidance capabilities (Wright, 2007). This in turn requires improved predictions/specifications of the atmosphere though which space objects fly. The variability of atmospheric drag forces exerted during severe magnetic storms poses a significant challenge to meeting this need.

Burke et al. (2007) showed that during the magnetic storms of November 2004 models used by SSN to predict stormtime thermospheric densities $(\rho)$ underestimate those inferred from accelerometers on the polar-orbiting Gravity Recovery and Climate Experiment (GRACE) satellites by more than $100 \%$. GRACE's orbital plane was in the noonmidnight meridian at an altitude of $\sim 487 \mathrm{~km}$. Figure 2a compares variations of local $\rho$ (black) and orbit-averaged $\bar{\rho}$ (blue) mass densities with $-D_{s t}$ (red). Figure $2 \mathrm{~b}$ compares $\bar{\rho}$ with magnetospheric electric fields $\boldsymbol{\varepsilon}_{V S} \approx \Phi_{\mathrm{PC}} / 2 L_{Y} R_{E}$ estimated from parameters observed by the Advanced Composition Explorer (ACE) satellite near the $L_{1}$ point (Burke, 2007). The symbols $\Phi_{\mathrm{PC}}$ and $2 L_{Y} R_{E}$ represent the polar cap potential and magnetospheric width, respectively. Quasisinusoidal changes in pre-disturbance $\rho$ (Fig. 2a) reflect daynight and apogee-perigee orbital variations. Crossing the polar cap during the storm GRACE experienced large positive and negative " $\rho$ " spikes, as the spacecraft encountered head and tail winds driven by anti-sunward convecting ions. We note four features of the data: (1) while stormtime $\rho$ varied widely, $\bar{\rho}$ evolved systematically as magnetic activity progressed, (2) during the main and early recovery phases $D_{s t}$ and $\bar{\rho}$ were well correlated, (3) $\boldsymbol{\varepsilon}_{V S}$ anticipated $\bar{\rho}$ variations with lead times of 3 to $5 \mathrm{~h}$, and (4) $\bar{\rho}$ relaxed toward prestorm status at a much faster rate than $D_{s t}$.

Even allowing for "local turbulence" evident in stormtime traces of $\rho$, the first result suggested that on a global scale the thermosphere evolves like a large thermodynamic system that never strays far from diffusive equilibrium (Wilson et al., 2006). To the degree that this assessment is accurate the stormtime evolution of the global thermosphere can be understood in terms of the first law of thermodynamics: $d E_{t h}=C_{V} d T+d W_{g}$, where $d E_{\mathrm{th}}$, and $d T$ signify changes in the thermosphere's total energy and temperature, $d W_{g}$ represents work done against gravity and $C_{V}$ is the local heat capacity of thermospheric gases. As a matter of convenience in providing quantitative estimates we turned to the J77 atmospheric model (Jacchia, 1977).

J77 consists of a set of stable density and temperature profiles, each uniquely specified by the exospheric temperature $T_{\infty}$. The modeled atmosphere consists of a fixed number of diatomic $\left(\mathrm{N}_{2}, \mathrm{O}_{2}\right)$ and monatomic $(\mathrm{O}, \mathrm{Ar}, \mathrm{He}, \mathrm{H})$ species $(\sigma)$. At altitudes $\leq 90 \mathrm{~km}$, species are well mixed

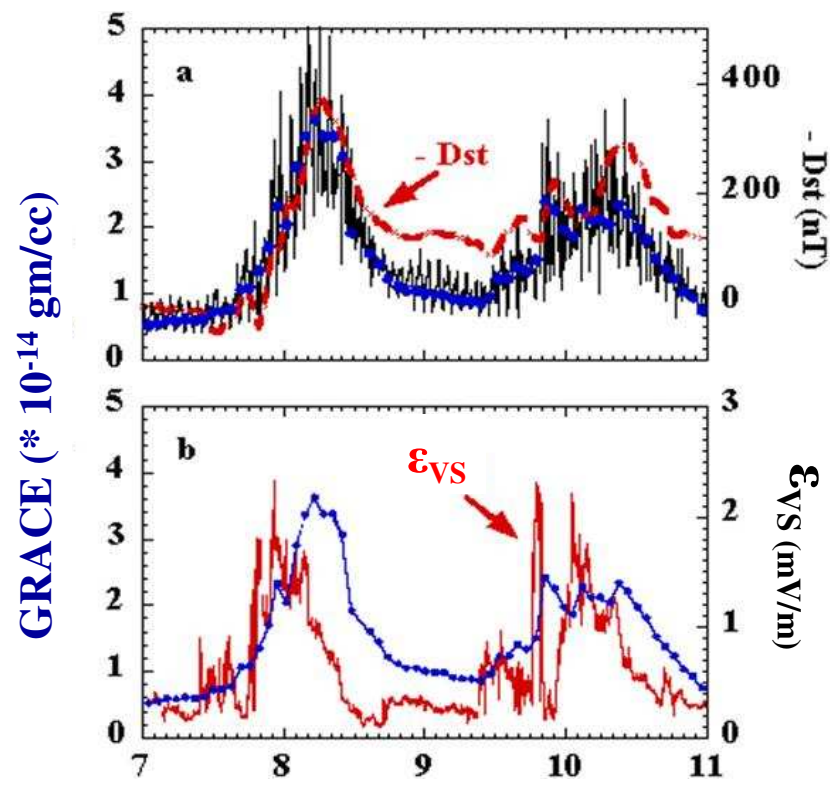

Fig. 2. (a) The black trace indicates mass densities measured by GRACE on 7-10 November 2004 at 10 s resolution. The red dashed line shows variations of $-D_{s t}$ over this period. Blue dots in both panels mark orbit-averaged densities. (b) The red trace indicates the electric field in the equatorial plane of the inner magnetosphere estimated from ACE measurements at $L_{1}$.

and maintain approximately the ground fractional densities. A minimum temperature of $188 \mathrm{~K}$ is assigned at $h=90 \mathrm{~km}$. Above $90 \mathrm{~km}$ all species are in diffusive equilibria specified by profiles $T(r)$ that asymptotically approach $T_{\infty}$ (cf. Appendix A). For calculations we define: number densities $n(r)=\sum_{\sigma}^{n_{\sigma}(r)}$, mean mass $\bar{m}(r)=\frac{1}{n(r)} \sum_{\sigma}^{m_{\sigma} n_{\sigma}(r)}$, mass densities $\bar{\rho}(r)=\bar{m}(r) n(r)$ and heat capacity

$$
\begin{aligned}
C_{V}(r) \approx \frac{k_{B} A}{n(r)} & \left\{\frac{5}{2}\left(n\left[\mathrm{~N}_{2}\right]+n\left[\mathrm{O}_{2}\right]\right)+\frac{3}{2}(n[\mathrm{O}]+n[\mathrm{Ar}]\right. \\
& +n[\mathrm{He}]+n[\mathrm{H}])\}
\end{aligned}
$$

where $r=R_{E}+h$ is distance from the Earth's center; $k_{B}$ and $A$ are Boltzmann's constant and Avogadro's number, respectively. The approximation sign in Eq. (1) recognizes the absence of chemical reactions in the J77 model. Figure 3a shows selected $\mathbf{J} 77$ density profiles appropriate for five values of $T_{\infty}$ between 800 and $2000 \mathrm{~K}$. These profiles indicate that at any given altitude a unique relationship exists between $\rho$ and $T_{\infty}$. Since $\bar{\rho}$ and the orbit-averaged altitude $(\bar{h})$ of GRACE are known it is possible to determine $T_{\infty}$. Leastsquare testing revealed relationships between $T_{\infty}$ and $\rho(h)$ found in $\mathrm{J} 77$ tables that are well represented in the form of a quadratic polynomial

$T_{\infty}=\sum_{i=0}^{2} a_{i}(h) \rho^{i}(\bar{h})$ 

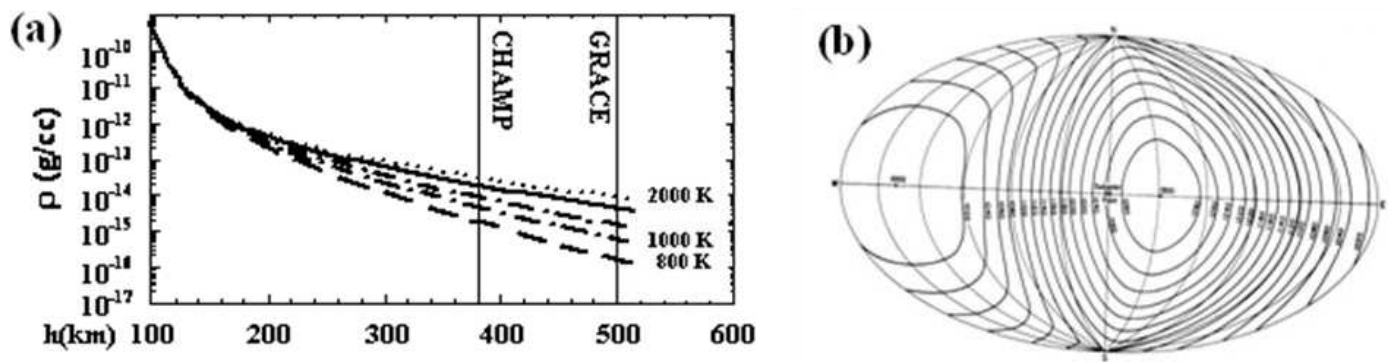

Fig. 3. (a) Mass density profiles as functions of altitude for five selected values of $T_{\infty}$. Vertical lines bound the range of altitudes of CHAMP and GRACE orbits in 2004. (b) Example of $\mathrm{J} 77 T_{\infty}$ distributions plotted on a latitude and local time grid.

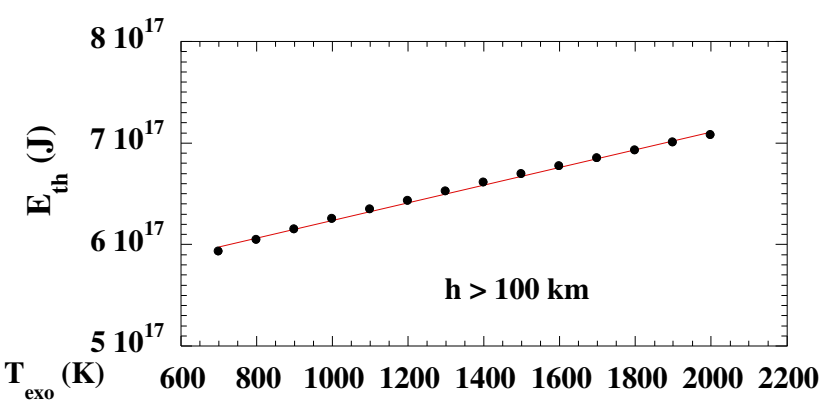

Fig. 4. $E_{\text {th }}$ estimated from $\mathbf{J} 77$ tables plotted as a function of globally-averaged exospheric temperatures.

In the $300 \leq \bar{h} \leq 500 \mathrm{~km}$ altitude range sampled by GRACE and CHAMP, the coefficients $a_{i}(\bar{h})$ are described by 5 th order polynomials of the form

$a_{i}(h)=\sum_{j=0}^{5} b_{i j} \bar{h}^{j}$

That is

$\left(\begin{array}{l}a_{0}(\bar{h}) \\ a_{1}(\bar{h}) \\ a_{2}(\bar{h})\end{array}\right)=$

$\left(\begin{array}{cccccc}-28.10 & 2.69 & -2.03 \times 10^{-3} & 0 & 0 & 0 \\ -4.733 \times 10^{17} & 4.312 \times 10^{15} & -1.372 \times 10^{13} & 1.60 \times 10^{10} & 0 & 0 \\ 3.2695 \times 10^{32} & -4.620 \times 10^{30} & 2.618 \times 10^{28} & -7.456 \times 10^{25} & 1.071 \times 10^{23} & -6.237 \times 10^{19}\end{array}\right)$

$\times\left(\begin{array}{c}1 \\ \bar{h} \\ \bar{h}^{2} \\ \bar{h}^{3} \\ \bar{h}^{4} \\ \bar{h}^{5}\end{array}\right)$

Regression coefficients obtained in fitting $T_{\infty}$ and $a_{i}$ to polynomials exceed 0.999. In applying Eqs. (2) and (3) $\bar{\rho}$ and $\bar{h}$ are in grams/cc and kilometers, respectively.

Figure $3 \mathrm{~b}$ shows an example of $T_{\infty}$ isotherm distributions for the $\mathrm{J} 77$ model plotted on a latitude-versus-local time (LT) grid. Note that $T_{\infty \text { min }}$ and $T_{\infty \text { max }}$ develop in the postmidnight and afternoon LT sectors. Their ratio is $\sim 1.3$ (Jacchia, 1977). Thus, polar-orbiting satellites should sample about the same value of $\bar{T}_{\infty} \approx 1.15 T_{\infty \text { min }}$ independent of the orbital plane's LT. We have compared values of $\bar{T}_{\infty}$ inferred via Eqs. (2) and (3) from simultaneous $\bar{\rho}$ measurements of CHAMP and GRACE during the summer months of 2004 (not shown). Consistent with our conjecture, inferred values of $\bar{T}_{\infty}$ agreed within $1 \%$. During this period the two spacecraft were separated by $\sim 90^{\circ}$ in LT and $>100 \mathrm{~km}$ in altitude.

The total thermospheric energy density is the sum of the thermal $\eta_{T}(r)=C_{V}(r) n(r) T(r) / A$, and potential energy contributions $\phi_{G}(r)=\rho(r) M_{E} G / r$. The symbols $M_{E}$ and $G$ represent the Earth's mass and the gravitational constant, respectively. To estimate the thermosphere's total energy content $E_{t h}=H_{T}+F_{G}$, it is necessary to integrate $\eta_{T}(r)$ and $\phi_{G}(r)$ over the volume of the thermosphere. In the present calculations we ignore local time effects and limit the range of integration from a selected altitude $h_{0} \geq 100 \mathrm{~km}$ to $1000 \mathrm{~km}$. Our use of orbit-averaged densities has already filtered latitudinal variations within the integrands. The total thermal energy within this altitude range is approximately

$$
H_{T} \approx 4 \pi \int_{R_{E}+h_{0}}^{R_{E}+1000} \eta(r) r^{2} d r=\frac{4 \pi}{A} \int_{R_{E}+h_{0}}^{R_{E}+1000} C_{V}(r) n(r) T(r) r^{2} d r
$$

Since we are only interested in changes in potential energy it is useful to set the potential energy of the thermosphere to zero at the base of the integration range (Wilson et al., 2006) and represent the total potential energy of thermospheric neutrals as

$$
\begin{aligned}
\Phi_{G} & \approx 4 \pi \int_{R_{E}+h_{0}}^{R_{E}+1000}\left[\phi(r)-\phi\left(r_{0}\right)\right] r^{2} d r \\
& =4 \pi M_{E} G \int_{R_{E}+h_{0}}^{R_{E}+1000} \rho(r)\left[\frac{1}{r}-\frac{1}{r_{0}}\right] r^{2} d r
\end{aligned}
$$

With information available in $\mathbf{J 7 7}$ tables it is possible to calculate the integrands of Eqs. (4) and (5) for $700 \leq T_{\infty} \leq 2000 \mathrm{~K}$ at increments of $100^{\circ}$ and integrate them from a base altitude of $100 \mathrm{~km}$ to obtain $E_{\mathrm{th}}$ as a function 

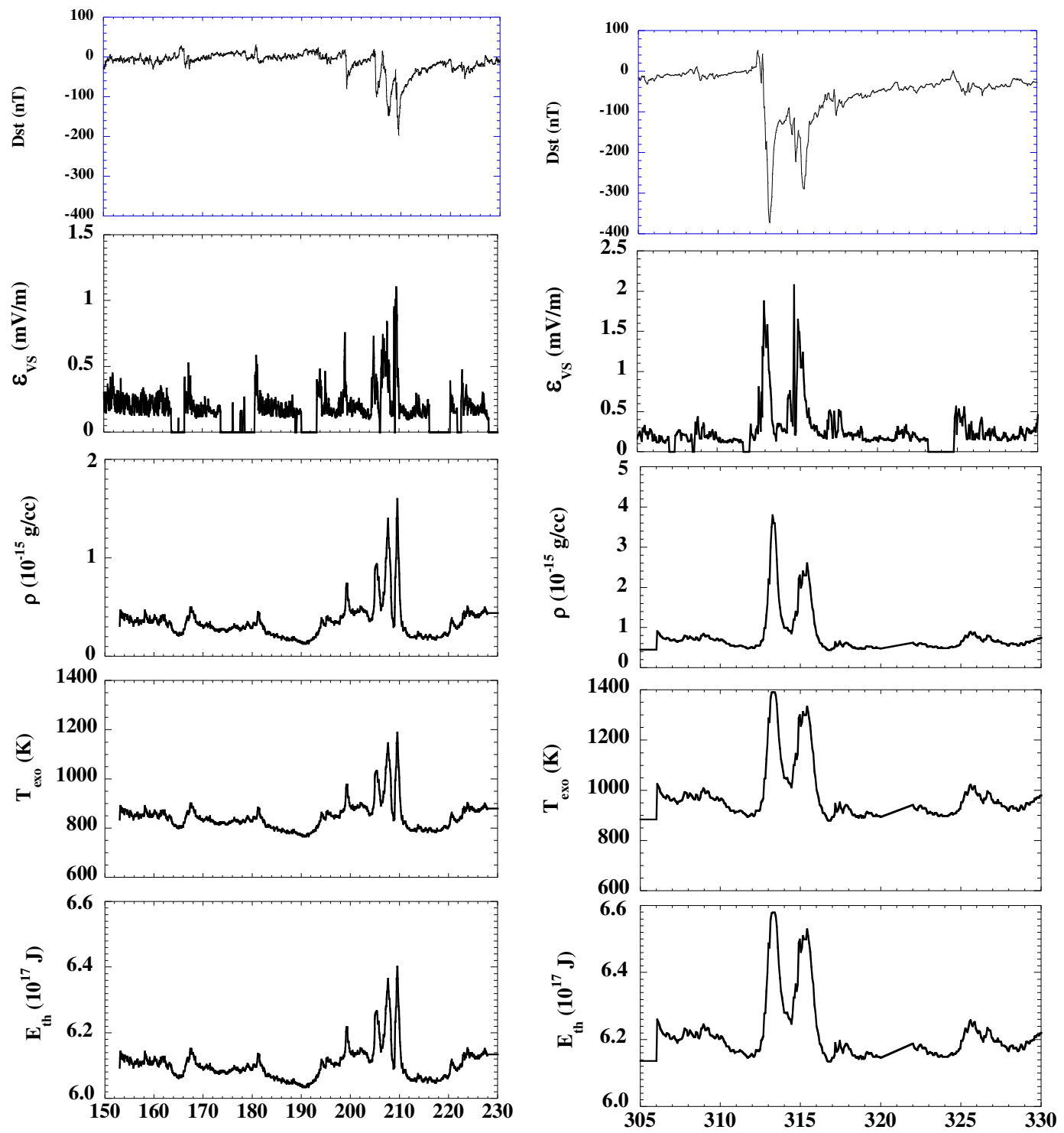

Fig. 5. Geophysical parameters and thermospheric responses plotted as functions of time for (a) Julian days 150 to 230 and (b) 306 to 330,2004 . From top to bottom the traces show the histories of the $D_{s t}$ index, $\boldsymbol{\varepsilon}_{V S}$, GRACE measurements of the orbit-averaged density, exospheric temperature and thermospheric energy.

of $T_{\infty}$. The lower limit of integration $h_{0}=100 \mathrm{~km}$ includes E-region contributions to the total thermospheric budget.

Figure 4 displays $E_{\text {th }}$ in Joules for $\bar{h} \geq 100 \mathrm{~km}$ obtained by numerical integrations of Eqs. (4) and (5) plotted as a function of $\bar{T}_{\infty}$. A linear regression analysis of these "data" shows that

$$
E_{\mathrm{th}}(h \geq 100 \mathrm{~km})=5.365 \times 10^{17}+8.727 \times 10^{13} \bar{T}_{\infty}
$$

with a regression coefficient $R>0.998$. A change of $100^{\circ}$ in $\bar{T}_{\infty}$ corresponds to a thermospheric energy gain/loss of $\sim 8.7 \times 10^{15} \mathrm{~J}$. Over the range $700 \leq T_{\infty} \leq 2000 \mathrm{~K}, E_{\text {th }}$ only varies by $\sim 15 \%$.
Figure 5a compares the geophysical parameters $D_{s t}$ (top) and $\boldsymbol{\varepsilon}_{V S}$ (second) with orbit-averaged measurements of $\bar{\rho}$ (third), $\bar{T}_{\infty}$ (fourth), and $E_{\text {th }}$ (bottom) acquired by GRACE between Julian days (JDs) 150 (1 June) and 230 (17 August) 2004. During this interval the orbital plane precessed from near the noon-midnight to the dawn-dusk meridian; $\bar{h}$ was $\sim 486.5 \mathrm{~km} . \bar{T}_{\infty}$ and $E_{\mathrm{th}}$ traces were obtained by applying Eqs. (2) and (6) to the $\bar{\rho}(t)$ stream and ranged between $\sim 750$ and $1200 \mathrm{~K}$ and $E_{\mathrm{th}}$ between 6.05 and $6.4 \times 10^{17} \mathrm{~J}$, respectively. The plots show $\bar{\rho}(t), \bar{T}_{\infty}$ and $E_{\text {th }}$ varying on two time scales: (1) low-frequency variations with the 27 day solar rotation period, and (2) spike-like outcrops that emerge in response to changes in geophysical conditions 


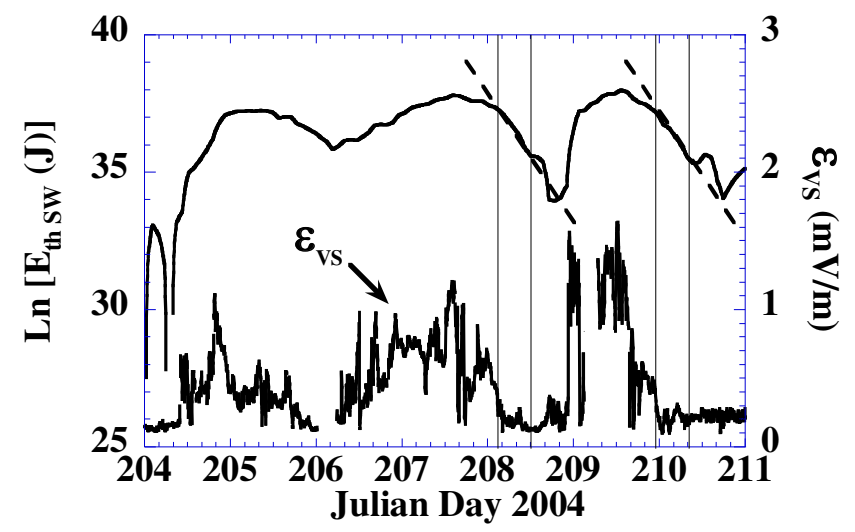

Fig. 6. Natural logarithm of $E_{\mathrm{th} \mathrm{SW}}$ and $\boldsymbol{\varepsilon}_{V S}$ for the disturbances on JDs 206-211, 2004. Vertical lines mark periods of decreased electric fields; slanted lines give the relaxation time $\tau_{E}$.

that correlate with intensifications of $D_{s t}$ and $\boldsymbol{\varepsilon}_{V S}$. Structures observed between JDs 204 and 211 are discussed below. However, we note that the largest change in the $E_{\text {th }}$ trace of $\sim 3 \times 10^{16} \mathrm{~J}$ occurred on JD 209 in response to interplanetary forcing when $D_{s t}$ attained a minimum value of about $-200 \mathrm{nT}$. The Dessler-Parker-Sckopke equation as formulated by Stern (2005) indicates that energy of the ring current $E_{\mathrm{RC}}$ increased by $\sim 5.16 \times 10^{15} \mathrm{~J}$. This is substantially less than the $\Delta E_{\text {th }}$ needed to account for observed $\bar{\rho}$ variations. Thus, while the ring current contributes to the energy of the upper atmosphere through particle precipitation and Poynting flux associated with Region 2 field-aligned currents, it cannot be the main reservoir from which the stormtime thermosphere draws energy. Rather, some large fraction of the thermosphere's energy budget must come from the solar wind unmediated by the ring current.

Figure $5 \mathrm{~b}$ compares the same geophysical and GRACE parameters measured during JDs 305-330 (2-27 November) 2004. The orbital plane of GRACE was again near the noon-midnight meridian. The $D_{s t}$ plot shows that two magnetic disturbances occurred between 7 and 10 November. Similar disturbances appear on all of the other plots. $D_{s t}$ minima were $-373 \mathrm{nT}$ (06:00 UT, 8 November) and $-289 \mathrm{nT}$ (10:00 UT, 10 November). Corresponding $E_{\mathrm{RC}}$ values are 9.62 and $7.46 \times 10^{15} \mathrm{~J}$. The pre-disturbance baselines for $\bar{T}_{\infty}$ and $E_{\text {th }}$ were near $900 \mathrm{~K}$ and $6.15 \times 10^{17} \mathrm{~J}$, respectively. $\bar{T}_{\infty}$ rose to $1390 \mathrm{~K}$ at 07:00 UT on JD 313 and $1350 \mathrm{~K}$ at 10:00 UT on JD 315. $E_{\text {th }}$ maxima at these times were 6.58 and $6.52 \times 10^{17} \mathrm{~J}$. Again, corresponding $\Delta E_{\text {th }}$ values of 4.3 and $3.7 \times 10^{16} \mathrm{~J}$ greatly exceed estimates of $E_{\mathrm{RC}}$.

In surveying several years of stormtime $\bar{\rho}(t), \bar{T}_{\infty}$ and $E_{\text {th }}$ inferred from measurements by accelerometers on the CHAMP and GRACE satellites it became apparent that outcrops above solar UV-induced backgrounds coincide with increases in $\boldsymbol{\varepsilon}_{V S}$. Moreover, as $\boldsymbol{\varepsilon}_{V S} \rightarrow 0, E_{\text {th }}$ always relaxes at the same rate. To quantify the relaxation rate $\left(1 / \tau_{E}\right)$ of $E_{\mathrm{th}}$,
Fig. 6 shows traces of $\boldsymbol{\varepsilon}_{V S}$ and the natural logarithm of $E_{\mathrm{th}}$ plotted as functions of time through the disturbed interval on JDs 204-211, 2004. Vertical lines highlight times when $\boldsymbol{\varepsilon}_{V S}$ decreased to low values. Slanted lines with the same slopes mark thermospheric responses to the removal of $\boldsymbol{\varepsilon}_{V S}$ driving. Numerically, the e-fold relaxation time of $E_{\text {th }}$ is $\tau_{E} \approx 6.5 \mathrm{~h}$.

Within the context of $\mathbf{J 7 7}$, application of the first law of thermodynamics to accelerometer data streams allows us to infer the values of $\bar{T}_{\infty}$ and $E_{\text {th }}$ needed to explain observed levels of $\bar{\rho}(t)$. However, this "kinematic" exercise tells us little about the global dynamics responsible for the thermosphere's passing from one energy state to the next. Correlations between $\boldsymbol{\varepsilon}_{V S}$ and $E_{\text {th }}$ found in Fig. 5 suggest that $E_{t h} \approx E_{U V}+E_{S W}$ is driven by two independent but additive sources the solar ultraviolet (UV) radiance (Bowman et al., 2006) and the solar wind.

The variability of $E_{\text {th }}$ SW during magnetic disturbances correlates with changes in $\boldsymbol{\varepsilon}_{V S}$. Rather than seek statistical relationships between the two quantities, we propose to exploit implications of information contained in the decay characteristics seen in Fig. 6. Specifically, we postulate that on a global scale the stormtime thermosphere acts like a drivendissipative system. To the degree that this conjecture is correct, $E_{\text {th SW }}$ should evolve as

$$
\frac{d E_{\mathrm{thSW}}}{d t}=\alpha_{E} \boldsymbol{\varepsilon}_{V S}-\frac{E_{\mathrm{th} \mathrm{SW}}}{\tau_{E}}
$$

The coupling constant $\alpha_{E}$ and relaxation time $\tau_{E}=6.5 \mathrm{~h}$ must be determined empirically. Numerical solutions of Eq. (7) can then be compared with GRACE measurements to confirm or refute the driven-dissipative assumption. Numerical solutions take the form

$$
E_{\text {th SW }}\left(t_{n+1}\right)=\alpha_{E} \boldsymbol{\varepsilon}_{V S}\left(t_{n}\right) \Delta t+E_{\text {th SW }}\left(t_{n}\right)\left(1-\frac{\Delta t}{\tau_{E}}\right)
$$

where $\Delta t$ represents the time step between samples. For convenience we set $\Delta t=1 \mathrm{~h}$, and express $\varepsilon_{V S}$ in $\mathrm{mV} / \mathrm{m}$. In this case

$$
\begin{aligned}
E_{\mathrm{thSW}}\left(t_{n+1}\right) & =\alpha_{E} \boldsymbol{\varepsilon}_{V S}\left(t_{n}\right)+E_{\mathrm{thSW}}\left(t_{n}\right)\left(1-\frac{1}{\tau_{E}}\right) \\
& =\alpha_{E} \boldsymbol{\varepsilon}_{V S}\left(t_{n}\right)+.846 E_{\mathrm{thSW}}\left(t_{n}\right)
\end{aligned}
$$

Through trial-and-error comparisons of solutions to Eq. (8b) with GRACE measurements during JDs 150-230, 2004 we found that $\alpha_{E} \approx 5.5 \times 10^{15}[(\mathrm{~J} / \mathrm{h}) /(\mathrm{mV} / \mathrm{m})]$.

Figure 7 contains plots of $\boldsymbol{\varepsilon}_{V S}$ (black), solutions of Eq. (8b) (blue) and GRACE measurements of $E_{\text {th SW }}$ (red). Top and bottom panels represent the disturbed intervals in July and November 2004, respectively. In both cases we approximated $E_{\text {th SW }}$ as $E_{\text {th }}-6.1 \times 10^{17} \mathrm{~J}$. Since the $E_{\text {th SW }}$ calculations in Fig. 7 are presented in units of $10^{16} \mathrm{~J}, \alpha_{E} \approx 0.55$. Although $\alpha_{E}$ was determined using data from the summer of 2004, the predictions of Eq. (8b) also appear to be in good agreement with GRACE data during the November storms. 
Finally, we note that Bowman et al. (2008) applied a modified version of this approach to a large number of magnetic storms for which both CHAMP and GRACE accelerometer data are available. They were able to replicate the main features of measured stormtime density variations.

Weimer (2005) combined statistically determined models of high-latitude electrostatic and magnetic Euler potential responses to interplanetary changes to estimate Poynting fluxes into the global ionosphere and thermosphere. Hereafter we refer to this model as W5. The model uses solar wind/IMF measurements to predict distributions of Poynting flux into the northern and southern ionosphere. W5 requires no prior knowledge about ionospheric conductance. Integration over the affected areas provides the global rates of energy input $P_{\mathrm{W} 5}$.

On the other hand, $E_{\text {th }}$ values inferred from GRACE accelerometer measurements are snapshots that capture the thermosphere's total energy content averaged over orbital periods. GRACE data reflect compromises that the thermosphere strikes between power received from the solar wind and lost via radiative and heat conduction processes (Mlynczak et al., 2005). Equation (8b) provides a bridge between the two approaches. The term $\alpha_{\mathrm{E}} \boldsymbol{\varepsilon}_{\mathrm{VS}}$ represents the rate of energy input needed to drive the stormtime thermosphere and should be directly comparable with $P_{\mathrm{W} 5}$. Since $\alpha_{E} \approx 5.5 \times 10^{15}[(\mathrm{~J} / \mathrm{h}) /(\mathrm{mV} / \mathrm{m})]$ and $P_{\mathrm{W} 5}$ is in Watts we must divide by $3600 \mathrm{~s} / \mathrm{h}$ to obtain $\alpha_{E} \approx 1.528 \times 10^{12} \mathrm{~W} /(\mathrm{mV} / \mathrm{m})$ or $1.528 \mathrm{TW} /(\mathrm{mV} / \mathrm{m})$. Figure 8 shows plots of $P_{\mathrm{W} 5}$ (red) at a 5-min cadence and hourly-averaged $\alpha_{\mathrm{E}} \boldsymbol{\varepsilon}_{\mathrm{VS}}$ in TW for the storms of July and November 2004. Both the $\alpha_{\mathrm{E}} \boldsymbol{\varepsilon}_{\mathrm{VS}}$ and $P_{\mathrm{W} 5}$ traces were time shifted by $1 \mathrm{~h}$ to allow for transport from ACE to the magnetosphere. In general delay times used in W5 vary according to the speed of the solar wind and the tilt angle of surfaces of constant phase for the interplanetary electric field (Weimer et al., 2002). Agreement between $P_{\mathrm{W} 5}$ and the energy requirements of GRACE is qualitatively good. Thus, on a global scale power inputs predicted by W5 are not inconsistent with GRACE measurements. Consequently, $P_{\mathrm{W} 5}$ as well as $\alpha_{\mathrm{E}} \boldsymbol{\varepsilon}_{\mathrm{VS}}$ can probably be used in Eq. (8a) to estimate the development of $E_{\text {th SW }}$.

Attention is directed to two particular aspects of the results shown in Fig. 8: (1) GRACE measurements and W5 predictions indicate sustained electromagnetic power input $\geq 1 \mathrm{TW}$ during both the July and November storms. This is greater than the stormtime inputs due to energetic particle precipitation and from solar UV (Knipp et al., 2005). (2) During the third disturbance of the July period and the first one of the November storms, $P_{\mathrm{W} 5}>\alpha_{\mathrm{E}} \boldsymbol{\varepsilon}_{\mathrm{VS}}$ by significant amounts. This discrepancy probably reflects the different estimates of $\Phi_{\text {PC }}$ In both instances the polar cap potential used in W5 was larger than that predicted by Burke (2007). For a given system of field-aligned currents the one driven by the higher $\Phi_{\mathrm{PC}}$ requires a higher power input to overcome collisional drag exerted by neutrals on $\boldsymbol{E} \times \boldsymbol{B}$ drifting ions.

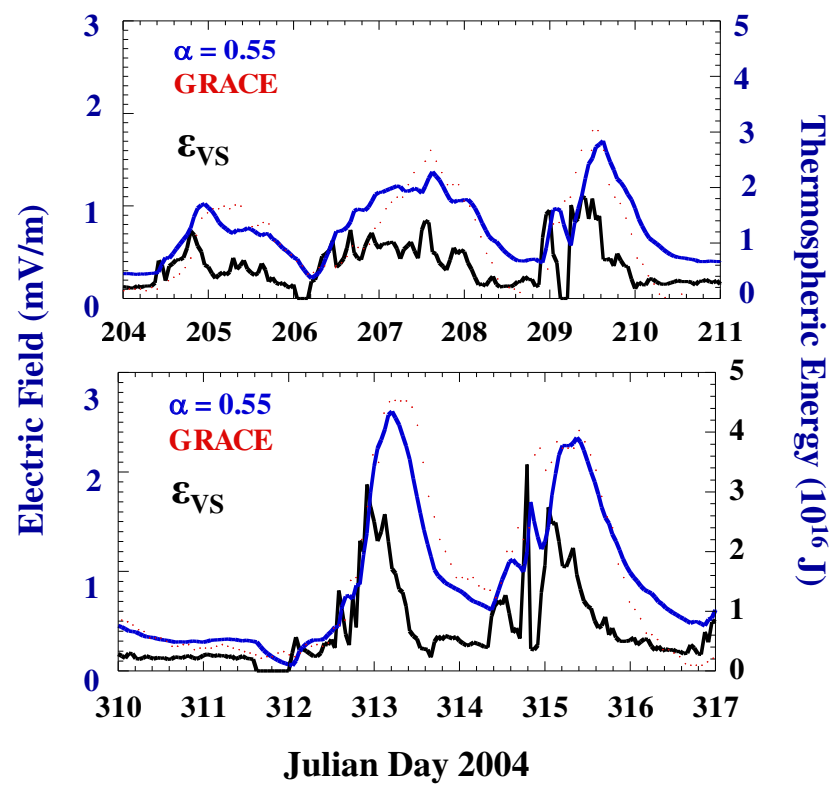

Fig. 7. Comparison of $\boldsymbol{\varepsilon}_{V S}$ (black), modeled $E_{\text {th SW (blue) and }}$ values inferred from density measurements by GRACE (red) plotted as functions of time during magnetically disturbed periods of July (top) and November (bottom) 2004. Energies are expressed in units of $10^{16} \mathrm{~J}$.

\section{Summary and discussion}

Data shown in previous sections exemplify two common stormtime phenomena: (1) Intense EPB activity in the main phase is followed by prolonged absences during recovery (Huang et al., 2001). (2) At topside altitudes orbit-averaged densities increase as $D_{s t}$ and $\varepsilon_{\mathrm{VS}}$ intensify in the main phase then revert to near quiet-time values by $\sim 10 \mathrm{~h}$ into recovery (Burke et al., 2007).

The temporal distribution of EPB detections before and during the magnetic storm of March 1991 (Fig. 1) suggests a basis for understanding the role of magnetospheric electric fields in driving the post-sunset equatorial ionosphere. During this storm CRRES measured sustained dawn-to dusk $\varepsilon_{M}$ earthward of the ring current into $L \approx 2$ throughout the main phase (cf. Fig. 2 of Wygant et al., 1998). Earthward of $L \approx 2$, the nominal $\pm 1^{\circ}$ uncertainty about spacecraft attitude leads to errors in measured $\boldsymbol{V} \times \boldsymbol{B}$ electric fields that are greater than the ambient $\varepsilon_{M}$, rendering CRRES double-probe data unusable for scientific analysis (Wygant et al., 1998). The durations of EPB detections are consistent with sustained electric field penetration throughout the main phase and during episodic reactivations of the ring current during recovery. In the low latitude ionosphere these penetration electric fields have eastward components near the dusk terminator (Wolf, 1970; Nopper and Carovillano, 1978) where they amplify normal PRE dynamics to increase the growth rate of the R-T instability (Ott, 1978). 


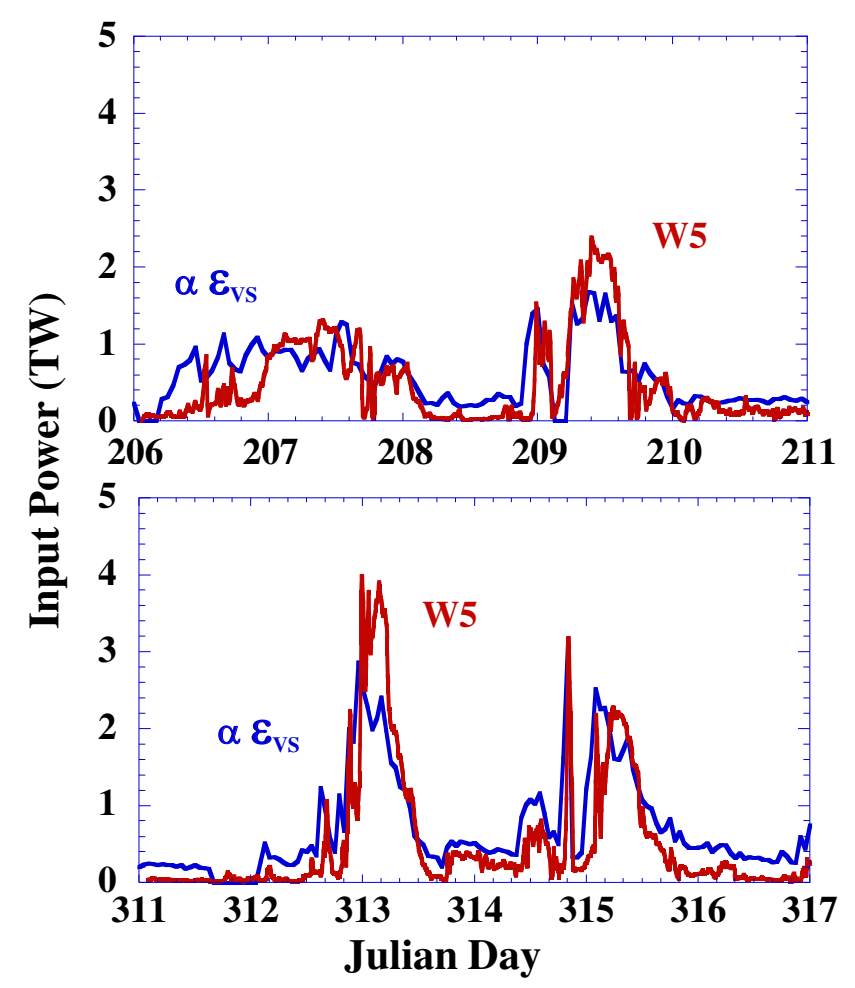

Fig. 8. Comparison of global power into the stormtime thermosphere predicted by the W5 model (red) and $\alpha \boldsymbol{\varepsilon}_{V S}$ (black) plotted as functions of time during the magnetically disturbed periods of July (top) and November (bottom) 2004.

Citing CRRES observations, Kikuchi et al. (2008) argued that enhanced equatorial electrojet signatures observed during the main phase of the 6 November 2001 magnetic storm indicate sustained $\boldsymbol{\varepsilon}_{M}$ penetration of the inner magnetosphere. This was followed by a 2 -h period in which the electrojet reversed polarity. Phenomenologically a counter electrojet can be ascribed to either over-shielding by residual Region 2 currents or the disturbance dynamo (Blanc and Richmond, 1980). Here, context favors an over-shielding interpretation. The November 2001 storm was unusual in that the main-phase $\Delta H$ only lasted $\sim 2 \mathrm{~h}$. It is difficult to understand how disturbance dynamo winds could affect equatorial electrodynamics in such a short time (Bruinsma and Forbes, 2007). Consistent with the $E_{\text {th }}-\varepsilon_{V S}$ relationship (Figs. 6 and 7 ), the over-shielding episode during early recovery marked the end of EPB activations and of significant magnetospheric involvement in stormtime ionosphere-thermosphere electrodynamics. Aside from the brief penetration events associated with ring-current activations, $\varepsilon_{M}$ remained near zero during the recovery phase (Wygant et al., 1998).

J77 provides a means to estimate $E_{\text {th }}$ from stormtime $\bar{\rho}$ variations through an application of the first law of thermodynamics. The evolution of $E_{\text {th }}$ shown in Fig. 6 suggests that on a global scale the thermosphere acts like a driven-dissipative system. Empirically established e-fold relaxation $\tau \approx 6.5 \mathrm{~h}$ and coupling $\alpha_{E} \approx 5.5 \times 10^{15}(\mathrm{~J} / \mathrm{h}) /(\mathrm{mV} / \mathrm{m})$ coefficients reproduced $E_{\text {th }} S W$ variations inferred from GRACE accelerometer data during magnetic storms. In substantial agreement with independent predictions of W5 (Weimer, 2005), the electromagnetic power $\alpha_{E} \boldsymbol{\varepsilon}_{V S}$ required to explain $\bar{\rho}$ variations during large storms was $1-3 \mathrm{TW}$, a factor of four larger than solar UV inputs to the dayside thermosphere during solar maximum (Knipp et al., 2005).

The sequential termination of $\boldsymbol{\varepsilon}_{V S}$ and the return of $E_{\text {th }}$ to pre-storm values do not imply that the thermosphere simultaneously reverts to its status quo ante at all localities. Some of the energy deposited during the main phase convects to subauroral latitudes as traveling atmospheric disturbances (TADs) that alter the thermospheric density and composition (Lin et al., 2005) at mid- to low latitudes. Observationally, TADs take $\sim 4 \mathrm{~h}$ to propagate from auroral to equatorial latitudes (Bruinsma and Forbes, 2007). After contributions from $\boldsymbol{\varepsilon}_{V S}$ and Region 2 currents turn off, residual thermospheric changes become the only agents capable of modulating an immediate restoration of the solar UV-driven dynamo that characterizes the quiet-time ionosphere.

Worldwide absences of EPBs for several days into recovery set lower bounds on the time required for full restoration of the PRE. Why should it take days for the solar UV driver to reestablish quite-time conditions at equatorial latitudes? The growth of the R-T instability responsible for EPB formation is abetted by the presence of eastward PRE electric fields and seeds of plasma irregularities that form at pre-dusk LTs. At least three broad types of stormtime thermospheric effects persist at low latitudes well into recovery. These are changes in the relative distributions of molecularatomic species, plasma densities and neutral winds. In combination all three affect the full redevelopment of the PRE that drives quiet-time EPBs. The remaining paragraphs consider a few plausible mechanisms.

Altered distributions of thermospheric species are reflected in UV radiances measured by the Thermosphere, Ionosphere, Mesosphere Energetics and Dynamics (TIMED) satellite during the magnetic storm of October 2003. Lin et al. (2005) showed that $\mathrm{O} / \mathrm{N}_{2}$ ratios in the equatorial F-layer decreased in the afternoon sector. Regions of low $\mathrm{O} / \mathrm{N}_{2}$ ratios were marked by reduced total electron content (TEC), indicating increased recombination rates in the $\mathrm{F}$ layer. Reported $\mathrm{O} / \mathrm{N}_{2}$ and TEC reductions at low latitudes persisted at least through the first full day of recovery. Lin et al. (2005) noted that late in the first day of recovery $135.6 \mathrm{~nm}$ emissions reappeared at off-equatorial latitudes and marked the initial restoration of the Appleton anomaly. Ionospheric uplift that produced the anomaly indicates a re-establishment of the Flayer dynamo responsible for bottomside irregularities seen in the recovery phase.

However, if plasma production in the dayside ionosphere falls below quiet-time equilibrium values, the polarization electric fields needed to maintain current continuity in the 
PRE sector decrease. Why might plasma density deficits continue long into recovery? The dominant source of dayside ionospheric plasma occurs via the photoionization of $\mathrm{NO}$, which is mostly created in the reaction $\mathrm{N}+\mathrm{O}_{2} \rightarrow \mathrm{NO}$. However, main phase Joule and solar UV heating of the dayside equatorial atmosphere transport $\mathrm{O}_{2}$ and other molecular species to altitudes higher than those of their quiet time equilibria. At the onset of recovery $\mathrm{O}_{2}$ densities should be relatively depleted at $\mathrm{E}$ layer altitudes. Since $\mathrm{O}_{2}$ is subject to dissociation from solar EUV, its restoration is not immediate. We expect that at the higher altitudes the two- $\left(\mathrm{O}+\mathrm{O} \rightarrow \mathrm{O}_{2}\right)$ and three- $\left(\mathrm{O}+\mathrm{O}+\mathrm{M} \rightarrow \mathrm{O}_{2}+\mathrm{M}\right)$ body interactions needed to restore $\mathrm{O}_{2}$ density distributions proceed slowly.

Most disturbance-dynamo wind modeling has concentrated on main and early recovery phase effects (e.g. Maruyama et al., 2005; Richmond et al., 2003). Huang et al. (2005) carried simulations 10 days into recovery and found that zonal disturbance winds persist long after driving ends. The meridional component evanesces quickly. Simulated disturbance winds near the equator at 120 and $300 \mathrm{~km}$ had westward velocity components of $\sim 50 \mathrm{~m} / \mathrm{s}$ for four days into recovery. Superposed on eastward daysidedynamo winds these fossil winds should reduce both $-\boldsymbol{u} \times \boldsymbol{B}$ electric fields near dusk and vertical wind shears at bottomside altitudes. Jicamarca radar measurements in the two days following the November 2004 magnetic storms are consistent with these conjectures (M. Hei, private communication, 2008). To the degree that these conditions are met they would reduce PRE amplitudes (Farley et al., 1986) and the formation of seeds for plasma density irregularities in the bottomside layer (Hysell and Kudeki, 2004). Both effects lower growth rates for irregularities via the R-T instability into nonlinear EPBs before zonal electric fields turn westward and thus stabilize bottomside plasma.

\section{Appendix A}

\section{The Jacchia (1977) model of the thermosphere}

J77 is a static model of thermospheric densities that uses analytically defined temperature profiles. It approximates the composition of the upper atmosphere as $\mathrm{N}_{2}, \mathrm{O}_{2}, \mathrm{O}, \mathrm{He}$, and $\mathrm{H}$ with all species having the same temperature profiles. The gases are considered well mixed below $100 \mathrm{~km}$ and in diffusive equilibrium above it. The mesopause is at the height $z_{o}=90 \mathrm{~km}$ where three boundary conditions are imposed: $\rho_{90}=3.43 \times 10^{-9} \mathrm{~g} / \mathrm{cc}, T_{90}=188 \mathrm{~K}$, and $d T_{90} / d z=0$. At the height $z_{x}=125 \mathrm{~km}$ all temperature profiles have inflection points; $d T_{x} / d z$ is continuous and $d^{2} T_{x} / d z^{2}=0 . T$ increases for $z>125 \mathrm{~km}$, asymptotically approaching an exospheric temperature $T_{\infty}$ at altitudes where the mean free paths of constituent gases become so long that thermal gradients are unsupportable. At the inflection point $T_{x}$ is a function of $T_{\infty}$ given by

$T_{x}=188+110.5 \operatorname{Sin} h^{-1}\left[.0045\left(T_{\infty}-188\right)\right]$
For $90 \leq z \leq 125 \mathrm{~km}$

$T=T_{x}+A \tan ^{-1}\left\{\frac{G_{x}}{A}\left(z-z_{x}\right)\left[1+1.7\left(\frac{\left(z-z_{x}\right)}{\left(z-z_{0}\right)}\right)^{2}\right]\right\}$

For $z \geq 125 \mathrm{~km}$

$T=T_{x}+A \tan ^{-1}\left\{\frac{G_{x}}{A}\left(z-z_{x}\right)\left[1+5.5 \cdot 10^{-5}\left(z-z_{x}\right)^{2}\right]\right\}$

where $G_{x}=1.9\left(\frac{T_{x}-188}{z_{x}-z_{0}}\right)$ and $A=(2 / \pi)\left(T_{\infty}-T_{x}\right)$.

Above $100 \mathrm{~km}$, the densities of individual species $n(i)$ are described by the diffusion equation

$\frac{d n(i)}{n(i)}=-\frac{m_{i} g}{T R^{*}} d z-\frac{d T}{T}\left(1+\alpha_{i}\right)$

where $m_{i}$ is the molecular weight of the $i$-th species, $\mathrm{g}$ is the local acceleration due to gravity at height $z, R^{*}=8.31432$ joules $/\left(\right.$ mole $\left.{ }^{\circ} \mathrm{K}\right)$ is the universal gas constant, and the thermal diffusion coefficient $\alpha_{i}=-0.38$ for helium and $\alpha_{i}=0$ for other species.

Acknowledgements. Research summarized here was supported by the Air Force Office of Scientific Research Task 2311SDA3 and reflects helpful discussions with David Anderson and Naomi Murayama of the University of Colorado, CIRES and Matthew Hei of Boston College. The authors are especially grateful for the help of L. C. Gentile of Boston College in preparing the manuscript for publication.

Topical Editor K. Kauristie thanks B. Bowman and another anonymous referee for their help in evaluating this paper.

\section{References}

Blanc, M. and Richmond, A. D.: The ionospheric disturbance dynamo, J. Geophys. Res., 85, 1669-1686, 1980.

Bowman, B. R., Tobiska, W. K., and Marcos, F. A.: A new empirical thermospheric density model JB2006 using new solar indices, AIAA 2006-6166, AIAA Astrodynamics Conference, Keystone, CO, 2006.

Bowman, B. R., Tobiska, W. K., Marcos, F. A., Huang, C. Y., Lin, C. S., and Burke, W. J.: A new empirical thermospheric density model JB2008 using solar and geomagnetic indices, AIAA 20086438, AIAA/AAS Astrodynamics Specialist Conference, 18-21 August 2008, Honolulu, HI, 2008.

Bruinsma, S. L. and Forbes, J. M.: Global observation of traveling atmospheric disturbances (TADs) in the thermosphere, Geophys. Res. Lett., 34, L14103, doi:10.1029/2007GL030243, 2007.

Burke, W. J., Maynard, N. C., Hagan, M. P., Wolf, R. A., Wilson, G. R., Gentile, L. C., Gussenhoven, M. S., Huang, C. Y., Garner, T. W., and Rich, F. J.: Electrodynamics of the inner magnetosphere observed in the dusk sector by CRRES and DMSP during the magnetic storm of June 4-6, 1991, J. Geophys. Res., 103, 29399_29418, 1998.

Burke, W. J., Gentile, L. C., Huang, C. Y., Valladares, C. E., and $\mathrm{Su}$, S.-Y.: Longitudinal variability of equatorial plasma bubbles observed by DMSP and ROCSAT-1, J. Geophys. Res., 109, A12301, doi:10.1029/2004JA010583, 2004. 
Burke, W. J.: Penetration electric fields: A Volland-Stern approach, J. Atmos. Solar-Terr. Phys., 69, 1114-1126, 2007.

Burke, W. J., Huang, C. Y., Marcos, F. A., and Wise, J. O.: Interplanetary control of thermospheric densities during large magnetic storms, J. Atmos. Solar-Terr. Phys., 69, 279-287, 2007.

Eccles, J. V.: Modeling investigation of the evening prereversal enhancement of the zonal electric field in the equatorial ionosphere, J. Geophys. Res., 103, 26709-26719, 1998.

Farley, D., Bonelli, E., Fejer, B., and Larsen, M.: The prereversal enhancement of the zonal electric field in the equatorial ionosphere, J. Geophys. Res., 91, 13723-13728, 1986.

Fejer, B. G. and Scherliess, L.: Time dependent responses of equatorial ionospheric electric fields to magnetospheric disturbances, Geophys. Res. Lett., 22, 851-854, 1995.

Fejer, B. G. and Scherliess, L.: Empirical models of storm time equatorial zonal electric fields, J. Geophys. Res., 102, 2404724056, 1997.

Fejer, B. G., Jensen, J. W., and Su, S.-Y.: Quiet time equatorial $\mathrm{F}$ region vertical plasma drift model derived from ROCSAT-1 observations, J. Geophys. Res., 113, A05304, doi:10.1029/2007JA012801, 2008.

Gentile, L. C., Burke, W. J., and Rich, F. J.: A global climatology for equatorial plasma bubbles in the topside ionosphere, Ann. Geophys., 24, 163-172, 2006,

http://www.ann-geophys.net/24/163/2006/.

Haerendel, G. and Eccles, J. V.: The role of the equatorial electrojet in the evening ionosphere, J. Geophys. Res., 97, 1181-1192, 1992.

Huang, C. M., Richmond, A. D., and Chen, M. Q.: Theoretical effects of geomagnetic activity on low-latitude electric fields, J. Geophys. Res., 110, A053124, doi:10.1029/2004JA010994, 2005.

Huang, C. Y., Burke, W. J., Machuzak, J. S., Gentile, L. C., and Sultan, P. J.: DMSP observations of equatorial plasma bubbles in the topside ionosphere near solar maximum, J. Geophys. Res., 106, 8131-8142, 2001.

Huang, C. Y., Burke, W. J., Machuzak, J. S., Gentile, L. C., and Sultan, P. J.: Equatorial plasma bubbles observed by DMSP satellites during a full solar cycle: Toward a global climatology, J. Geophys. Res., 107(A12), 1434, doi:10.1029/2002JA009452, 2002.

Hysell, D. L. and Kudeki, E.: Collisional shear instability in the equatorial F region ionosphere, J. Geophys. Res., 109, A11301, doi:10.1029/2004JA019636, 2004.

Jacchia, L. G.: Thermospheric temperature, density and composition: A new model, SAO Special Report 375, 1977.

Kelley, M. C., Makela, J. J., Chau, J. L., and Nicolls, M. J.: Penetration of the solar wind electric field into the magnetosphere/ionosphere system, Geophys. Res. Lett., 30(4), 1158, doi:10.1029/2002/GL016321, 2003.

Kikuchi, T., Hashimoto, K. K., and Nozaki, K.: Penetration of magnetospheric electric fields to the equator during geomagnetic storms, J. Geophys. Res., 113, A06214, doi:1029/2007JA012628, 2008.

Knipp, D. J., Tobiska, W. K., and Emery, B. A.: Direct and indirect thermospheric heating sources for solar cycles 21-23, Solar Phys., 224, 495-505, 2005.

Lin, C. H., Richmond, A. D., Liu, J. Y., Yeh, H. C., Paxton, L. J., Lu, G., Tsai, H. F., and Su, S.-Y.: Large-scale variations of the low-latitude ionosphere during the October-November 2003 superstorm: Observational results, J. Geophys. Res., 110, A09S28, doi:10.1029/2004JA010900, 2005.

Maruyama, N., Richmond, A. D., Fuller-Rowell, T. J., Codrescu, M. V., Sazykin, S., Toffoletto, F. R., Spiro, R. W., and Millward, G. H.: Interaction between direct penetration and disturbance dynamo electric fields in the storm-time equatorial ionosphere, Geophys. Res. Lett., 32, L17105, doi:10.1029/2005GL0023763, 2005.

Mlynczak, M. G., Martin-Torres, F. J., Crowley, G., Kratz, D. P., Funke, B., Lu, G., Lopez-Puertas, M., Russell, J. M., Kozyra, J., Mertens, C., Sharma, R., Gordley, L., Picard, R., Winick, J., and Paxton, L.: Energy transport in the thermosphere during the solar storms of April 2002, J. Geophys. Res., 110, A12S25, doi:1029/2005JA011141, 2005.

Nopper, R. W. and Carovillano, R. L.: Polar equatorial coupling during magnetically active periods, Geophys. Res. Lett., 5, 699702, 1978.

Ott, E.: Theory of Rayleigh-Taylor bubbles in the equatorial ionosphere, J. Geophys. Res., 83, 2066-2069, 1978.

Richmond, A. D., Peymirat, C., and Roble, R. G.: Long-lasting disturbances in the equatorial ionospheric electric field simulated with a coupled magnetosphere-ionosphere-thermosphere model, J. Geophys. Res., 108(A3), 1118, doi:10.1029/2002JA009758, 2003.

Scannapieco, A. J. and Ossakow, S. L.: Nonlinear equatorial spread F, Geophys. Res. Lett., 3, 451-455, 1976.

Scherliess, L. and Fejer, B. G.: Storm time dependence of equatorial disturbance dynamo zonal electric fields, J. Geophys. Res., 102, 24037-24046, 1997.

Singh, S., Johnson, F. S., and Power, R. A.: Gravity wave seeding of equatorial plasma bubbles, J. Geophys. Res., 102, 7399-7410, 1997.

Stern, D. P.: A historical introduction to the ring current, in The Inner Magnetosphere: Physics and Modeling, Geophys. Monogr. Series 155, Amer. Geophys. U., Washington, D.C., 1, doi:10.1029/155GM01, 2005.

Weimer, D. R., Ober, D. M., Maynard, N. C., Burke, W. J., Collier, M. R., McComas, D. J., Nagai, T., and Smith, C. W.: Variable time delays in the propagation of the interplanetary magnetic field, J. Geophys. Res., 107(A8), 1210, doi:10.1029/2001JA009102, 2002.

Weimer, D. R.: Improved ionospheric electrodynamic models and application to calculating Joule heating rates, J. Geophys. Res., 110, A05306, doi:10.1029/2005JA010884, 2005.

Wilson, G. R., Weimer, D. R., Wise, J. O., and Marcos, F. A.: Response of the thermosphere to Joule heating, J. Geophys. Res., 111, A10314, doi:10.1029/2006JA011274, 2006.

Wolf, R. A.: Effects of ionospheric conductivity on convective plasma flow in the magnetosphere, J. Geophys. Res., 75, 46774698, 1970.

Wright, D.: Space debris, Physics Today, 60, 10-35, 2007.

Wygant, J., Rowland, D., Singer, H. J., Temerin, M., Mozer, F., and Hudson, M. K.: Experimental evidence on the role of the large spatial scale electric field in creating the ring current, J. Geophys. Res., 103, 29527-29544, 1998. 